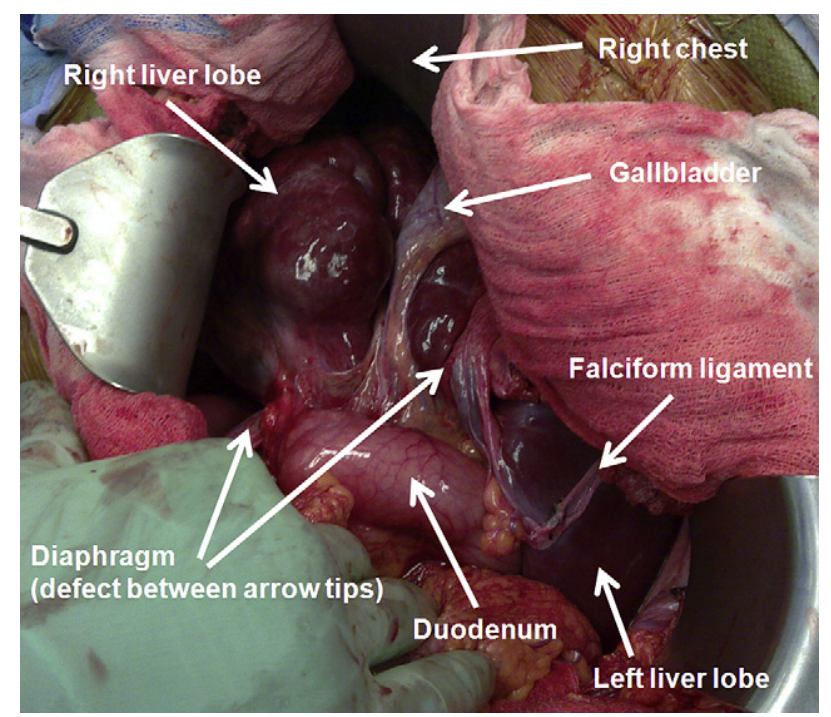

FIGURE 2. Intraoperative situs (right thoracoabdominal incision in the 8th intercostal space) showing the diaphragmatic defect with herniated and nodular right liver and healthy left liver. The herniated colon was already reduced out of the right side of the chest.

diaphragmatic hernia discovered in a 24-year-old woman. Results of imaging and pathologic examination were consistent with a Budd-Chiari syndrome limited to the right lobe of the liver. Moreover, a 1.1-cm hypervascular lesion was noted and the left lobe was hypertrophied, suggesting malfunction of the right lobe. Fortunately, the final pathologic examination did not reveal a hepatoma. A reversible Budd-Chiari-like syndrome in the liver has been described previously in 2 cases of hepatothorax after rupture of the right diaphragm. ${ }^{4}$ These patients had their diagnoses made within 15 months after the trauma, and venous outflow returned to normal after reintroduction of the liver into the abdominal cavity. In our case, the Budd-Chiari syndrome was considered to be irreversible as a result of right hepatic vein thrombosis and the very late presentation. The surgical indication was based on the radiographic finding of a hypervascular lesion (possibly a hepatoma) of $1.1 \mathrm{~cm}$ and on the need for repair of the symptomatic diaphragmatic hernia. We chose a thoracoabdominal approach, and primary suture closure of the diaphragmatic repair was sufficient, although other surgeons have previously described prosthetic mesh reinforcement. $^{5}$

Taken together, this is the first report of hepatothorax with an irreversible Budd-Chiari syndrome in a patient with post-traumatic diaphragmatic rupture, treated by right hepatectomy and primary diaphragmatic repair.

\section{References}

1. Crandall M, Popowich D, Shapiro M, West M. Posttraumatic hernias: historical overview and review of the literature. Am Surg. 2007;73:845-50.

2. Shreck GL, Toalson TW. Delayed presentation of traumatic rupture of the diaphragm. J Okla State Med Assoc. 2003;96:181-3.

3. Igai H, Yokomise H, Kumagai K, Yamashita S, Kawakita K, Kuroda Y. Delayed hepatothorax due to right-sided traumatic diaphragmatic rupture. Gen Thorac Cardiovasc Surg. 2007;55:434-6.

4. Fernandez-González AL, Llorens R, Herreros JM, Cato J, Lecumberri F, Longo J. Blunt traumatic rupture of the right hemidiaphragm and Budd-Chiari syndrome. Ann Thorac Surg. 1994;58:559-61.

5. Seket B, Henry L, Adham M, Partensky C. Right-sided posttraumatic diaphragmatic rupture and delayed hepatic hernia. Hepatogastroenterology. 2009;56: $504-7$

\title{
Removal of a large cement embolus from the right pulmonary artery 4 years after kyphoplasty: Consideration of thrombogenicity
}

\author{
Dagmar Kollmann, MD, ${ }^{\mathrm{a}}$ Konrad Hoetzenecker, MD, ${ }^{\mathrm{a}}$ Helmut Prosch, MD, ${ }^{\mathrm{b}}$ Hendrik J. Ankersmit, MD, ${ }^{\mathrm{a}}$ \\ Clemens Aigner, MD, ${ }^{\mathrm{a}}$ Shahrokh Taghavi, MD, ${ }^{\mathrm{a}}$ and Walter Klepetko, MD, ${ }^{\mathrm{a}}$ Vienna, Austria
}

\footnotetext{
From the Departments of Thoracic Surgery ${ }^{\mathrm{a}}$ and Radiology, ${ }^{\mathrm{b}}$ Medical University of Vienna, Vienna, Austria.

Disclosures: Authors have nothing to disclose with regard to commercial support.

D.K. and K.H. are equal joint first authors.

Received for publication Oct 6,2011; revisions received Dec 17, 2011; accepted for publication Jan 13, 2012

Address for reprints: Konrad Hoetzenecker, MD, Department of Thoracic Surgery, Medical University of Vienna, Währinger Gürtel 18-20, 1090 Vienna, Austria

(E-mail: konrad.hoetzenecker@meduniwien.ac.at).

J Thorac Cardiovasc Surg 2012;143:e22-4

$0022-5223 / \$ 36.00$

Copyright (C) 2012 by The American Association for Thoracic Surgery

doi: $10.1016 /$ j.jtcvs.2012.01.050
}

Percutaneous kyphoplasty is a minimally invasive procedure that has become a standard treatment for compression fractures of the spine. According to the literature, leakage of bone cement into paravertebral venous system occurs in a high percentage of cases. ${ }^{1}$ From that point, the cement can drift toward the right side of the heart and the pulmonary circulation. Current recommendations include a warfarin anticoagulant therapeutic regimen for 3 to 6 months to avoid thrombus formation on the cement embolus. Because these recommendations are solely based on case reports, however, they do not exceed evidence grade IV according to the 

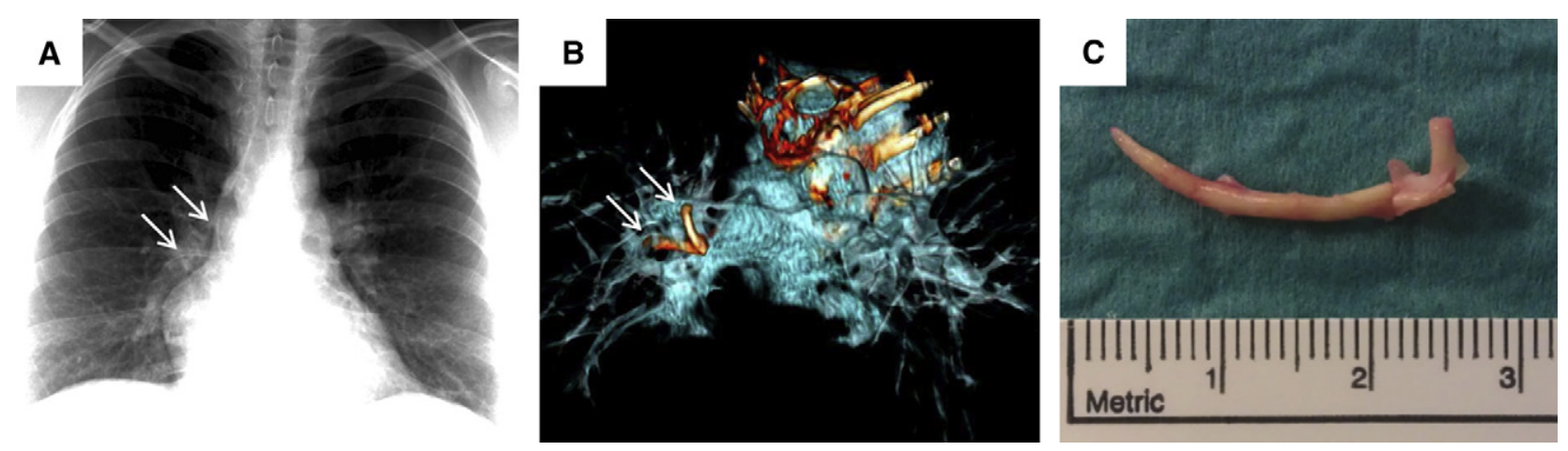

FIGURE 1. A, The chest radiograph showed the incidental finding of a cement embolus projecting over the right lung hilum. B, Workup with computed tomography revealed a string-formed cement embolus in the right pulmonary artery. C, Gross examination of the removed foreign body showed complete endothelialized cement embolus without any signs of attached thrombotic material.

Oxford criteria for evidence-based medicine. ${ }^{2}$ On the other hand, there is clear in vitro evidence that the bone cements in current use are not thrombogenic. ${ }^{3}$ Here we report the case of a patient with a large cement embolus that was removed 4 years after kyphoplasty. No evidence of thrombus formation was found on the removed foreign body.

\section{CLINICAL SUMMARY}

A 35-year-old woman was seen at the outpatient ward with a chest radiograph showing an L-shaped object projecting over the right hilum (Figure 1, A). A consecutively performed computed tomographic scan revealed a foreign body localized in the right pulmonary artery. One arm of the foreign body perforated the vessel wall and was located mediastinal (Figure 1, B). In addition, millimeter-sized, radiopaque particles were found in the azygos vein. Specific questioning revealed that the patient had undergone a kyphoplasty procedure with polymethylmethacrylate bone cement to treat 4 vertebral compression fractures (T5, T7, T8, T10) that had occurred after extensive horseback riding 4 years earlier. The foreign body had the same pattern of radiation absorption as the bone cement used for the fixation of the vertebral fractures. The patient reported constant pain in her spine since the accident leading to the kyphoplasty; otherwise, she was free of comorbidities. Because the thrombogenicity of polymethylmethacrylate embolization to pulmonary vessels is still under discussion and the patient insisted that the foreign body be removed surgically, we offered the patient operative treatment. A median sternotomy was performed, the right pulmonary artery was opened longitudinally under cardiopulmonary bypass, and the intravasal part of the foreign body was completely removed. Gross examination revealed a solid gray string about 25 $\mathrm{mm}$ long. The surface of the cement embolus was covered with neointima, and no signs of attached thrombotic material could be found (Figure 1,C). The postoperative course was uneventful, and the patient could be discharged 5 days after the operation.

\section{DISCUSSION}

Cement embolization to the pulmonary artery through leakage of insufficiently polymerized polymethylmethacrylate into paravertebral veins is a common finding after percutaneous kyphoplasty. ${ }^{1}$ In most cases, the embolization is asymptomatic; however, cases of right ventricular perforation have been described in the literature. ${ }^{4}$ Although pulmonary cement embolism is common, there is still no clear treatment strategy, mainly because of the poor quality of published case series. There is sufficient evidence that acrylic bone cement is not thrombogenic in vitro. In 1 study, not only did polymerized bone cement not induce platelet aggregation as measured with light transmission aggregometry, the liquid components of polymethylmethacrylate even prolonged the partial thromboplastin time. ${ }^{3}$ Despite this finding, a warfarin anticoagulation therapeutic regimen for 3 to 6 months is currently recommended. ${ }^{2}$

This case report gives important information on the thrombogenicity of polymethylmethacrylate in vivo. Even 4 years after embolization to the pulmonary artery, the removed cement piece did not show any signs of thrombus formation on its surface, although the patient had not received anticoagulants. Our finding is in contrast to a case report of Lim and colleagues, ${ }^{5}$ who found a thrombus in the right atrium next to 2 polymethylmethacrylate strings. In that case, however, gross examination showed no attachment of thrombus to the cement. In our opinion, the thrombus may have been indirectly caused by generation of a turbulent flow rather than by direct thrombogenicity of the material.

We therefore conclude that a polymethylmethacrylate embolus located in large pulmonary vessels might not necessitate anticoagulation; however, patients could benefit from a coumarin therapeutic regimen if the right atrium is involved. According to the guidelines, surgical removal of the cement embolus should be performed in patients with a symptomatic central embolism. A prospective clinical trial is required to address the issue of anticoagulation at a higher level of evidence. 


\section{References}

1. Choe DH, Marom EM, Ahrar K, Truong MT, Madewell JE. Pulmonary embolism of polymethyl methacrylate during percutaneous vertebroplasty and kyphoplasty. AJR Am J Roentgenol. 2004;183:1097-102.

2. Krueger A, Bliemel C, Zettl R, Ruchholtz S. Management of pulmonary cement embolism after percutaneous vertebroplasty and kyphoplasty: a systematic review of the literature. Eur Spine J. 2009;18:1257-65.
3. Blinc A, Bozic M, Vengust R, Stegnar M. Methyl-methacrylate bone cement surface does not promote platelet aggregation or plasma coagulation in vitro. Thromb Res. 2004; 114:179-84.

4. Son KH, Chung JH, Sun K, Son HS. Cardiac perforation and tricuspid regurgitation as a complication of percutaneous vertebroplasty. Eur J Cardiothorac Surg. 2008;33:508-9.

5. Lim KJ, Yoon SZ, Jeon YS, Bahk JH, Kim CS, Lee JH, et al. An intraatrial thrombus and pulmonary thromboembolism as a late complication of percutaneous vertebroplasty. Anesth Analg. 2007;104:924-6.

\title{
Attenuation of bone morphogenetic protein receptor type 2 expression in the pulmonary arteries of patients with failed Fontan circulation
}

\author{
Hidekazu Ishida, MD, Shigetoyo Kogaki, MD, Kunihiko Takahashi, MD, PhD, and \\ Keiichi Ozono, MD, PhD, Osaka, Japan
}

The Fontan procedure is a standard treatment for complex congenital heart defects when biventricular repair cannot be performed. Although the outcomes of the Fontan procedure have been improved recently, some patients still have failure of the Fontan circulation, with consequences such as exercise intolerance, protein-losing enteropathy, and plastic bronchitis, which is at least partially attributable to high

From the Department of Pediatrics, Osaka University Graduate School of Medicine, Osaka, Japan.

Disclosures: Authors have nothing to disclose with regard to commercial support. Received for publication May 17, 2011; revisions received Sept 20, 2011; accepted for publication Dec 8, 2011; available ahead of print Feb 17, 2012.

Address for reprints: Shigetoyo Kogaki, MD, 2-2 Yamadaoka, Suita, Osaka 565-

0871, Japan (E-mail: skogaki@ped.med.osaka-u.ac.jp).

J Thorac Cardiovasc Surg 2012;143:e24-6

$0022-5223 / \$ 36.00$

Copyright $(c) 2012$ by The American Association for Thoracic Surgery

doi:10.1016/j.jtcvs.2011.12.064 pulmonary vascular resistance. We previously reported that endothelin-1 and its receptors were overexpressed in the pulmonary arteries of patients with failed Fontan circulation ${ }^{1}$; however, the pathobiology of pulmonary arterial remodeling in these patients remains unclear.

Because heterozygous mutations in bone morphogenetic protein receptor type 2 (BMPR2) have been identified in patients with familial and idiopathic pulmonary arterial hypertension, bone morphogenetic protein (BMP) and its signal transduction were thought to be critical in pulmonary arterial hypertension pathogenesis. ${ }^{2}$ Bone morphogenetic protein signaling plays a pivotal role in regulating cell proliferation, differentiation, and apoptosis. Impairment of BMPR2 function thus may cause pulmonary vascular remodeling and increase pulmonary vascular resistance. Previous studies have shown that reduced BMPR2 expression is also associated with secondary pulmonary arterial hypertension. Our study is the first to demonstrate attenuation of

TABLE 1. Clinical characteristics and hemodynamic data of the patients

\begin{tabular}{|c|c|c|c|c|c|c|c|c|c|c|c|c|}
\hline \multirow{2}{*}{$\begin{array}{c}\text { Patient } \\
\text { no. }\end{array}$} & \multirow[b]{2}{*}{ Sex } & \multirow[b]{2}{*}{ Diagnosis } & \multicolumn{2}{|c|}{ Fontan } & \multicolumn{2}{|c|}{ Death } & \multicolumn{2}{|c|}{ MPAP (mm Hg) } & \multicolumn{2}{|c|}{ TPG (mm Hg) } & \multicolumn{2}{|c|}{$\operatorname{PVR}\left(\mathbf{U} / \mathbf{m}^{2}\right)$} \\
\hline & & & Age (y) & Type & Age (y) & Cause & Pre & Post & Pre & Post & Pre & Post \\
\hline 1 & $\mathrm{~F}$ & SV & 9 & APC & 20 & $\mathrm{HF}$ & 12 & 11 & 6 & 3 & 1.0 & 2.3 \\
\hline 2 & M & SV & 16 & LT & 18 & $\mathrm{FF}$ & 13 & 26 & 5 & 14 & 1.6 & 3.8 \\
\hline 3 & $\mathrm{~F}$ & PAIVS & 8 & APC & 13 & FF & 12 & 16 & 6 & 7 & 0.9 & 3.6 \\
\hline 4 & M & SV & 8 & APC & 15 & $\mathrm{FF}$ & 9 & 13 & 5 & 9 & 1.2 & 3.8 \\
\hline 5 & $\mathrm{~F}$ & DORV & 3 & LT & 13 & $\mathrm{HF}$ & 15 & 22 & 4 & 5 & 3.0 & 3.1 \\
\hline 6 & M & SV & 3 & LT & 4 & Inf & 10 & 15 & 6 & 5 & 2.0 & NA \\
\hline 7 & M & SV & 3 & LT & 3 & $\mathrm{FF}$ & 14 & 18 & 6 & 16 & 1.4 & NA \\
\hline 8 & $\mathrm{~F}$ & DORV & 2 & $\mathrm{ECC}$ & 3 & $\mathrm{HF}$ & 18 & 13 & 5 & 4 & 2.2 & 1.9 \\
\hline 9 & $\mathrm{~F}$ & $\mathrm{TA}$ & 7 & APC & 16 & SD & 11 & NA & 5 & NA & 1.0 & NA \\
\hline 10 & $\mathrm{M}$ & SV & 4 & ECC & 7 & SD & 10 & 9 & 7 & 5 & 0.8 & 2.6 \\
\hline
\end{tabular}

MPAP, Mean pulmonary arterial pressure; TPG, transpulmonary gradient; PVR, pulmonary vascular resistance; Pre, before Fontan operation; Post, after Fontan operation; SV, single ventricle; $A P C$, atriopulmonary connection; HF, heart failure; $L T$, lateral tunnel; $F F$, Fontan failure; PAIVS, pulmonary atresia with intact ventricular septum; $D O R V$, double-outlet right ventricle; Inf, infection; $N A$, not available; $E C C$, extracardiac conduit; $T A$, tricuspid atresia; $S D$, sudden cardiac death. 